\title{
Coping with loneliness: Caregivers of cancer patients
}

\author{
Ami Rokach ${ }^{1,2}$, Yona Miller², Sharon Schick², Michaela Bercovitch ${ }^{3}$ \\ 1. Psychology Department, York University, Canada. 2. Center for Academic Studies, Israel. 3. Palliative Care Department, \\ Sheba Medical Center, Israel.
}

Correspondence: Ami Rokach. Address: Psychology Department, York University, Canada. Email: arokach@yorku.ca

Received: September 26, 2013 Accepted: December 23, 2013

Online Published: February 17, 2014

DOI : $10.5430 /$ cns.v2n2p42

URL: http://dx.doi.org/10.5430/cns.v2n2p42

\section{Abstract}

Caregivers to cancer patients may be particularly vulnerable to the experience of loneliness. The current study compared the strategies used to cope with loneliness by those caring for hospitalized cancer patients who were receiving treatment, and caregivers of cancer patients in a hospice, who were on their death bed. Analyses revealed that there was no significant difference in coping with loneliness by caregivers of the ill and dying, but found a significant interaction effect within the caregivers to the ill group. Women attending to the ill scored higher on Acceptance and reflection, Self-development \& understanding, and on the Social support network subscales than men did.

\section{Key words}

Caregivers, Loneliness, Cancer, Patients, Death

\section{Introduction}

Approximately 65 million Americans serve as caregivers for an ill adult ${ }^{[1]}$ with this role commonly assumed by family members. Cancer patients rely almost always on family, friends, and significant others to help them navigate the rough terrain of their illness. This study focuses on the loneliness experienced by two caregiver groups: those who care for hospitalized cancer patients and the caregivers who accompany patients with terminal cancer in their last leg of the journey, while they were hospitalized in a hospice. We examined the coping with loneliness of those two groups.

Cancer has a profound effect on the lives of patients and their caregivers, with loneliness being among the more significant psychosocial consequences ${ }^{[15]}$. It produces physical changes that may be aversive to others ${ }^{[29]}$. For example, during treatment, patients may experience bleeding tendencies, hair loss, mouth sores, and unattractive skin reactions ${ }^{[34]}$. Unfortunately, cancer patients, while they must face what may be the most stressful time in their lives, they may also face a decrease in their social support resources. That places their caregivers as the most suitable to offer support, assistance, and possibly love, which may prove to be instrumental during the course of illness and recovery ${ }^{[11,16]}$.

Because it is part of human nature to avoid pain, cancer patients and their families often experience tremendous difficulty relating to each other and working with the problem at hand in a constructive way. Finally, as the cancer progresses, opportunities for social activities decrease due to disabilities caused by the disease ${ }^{[3]}$. Friedman et al. ${ }^{[12]}$ observed that approximately $50 \%$ of their 60 sick participants felt that their loneliness was associated with illness or illness-related situations. 


\subsection{Caregivers}

"Rosalyn Carter is quoted as saying [that] there are four types of people: those who are caregivers; those who have been caregivers; those who will be caregivers; and those who will need caregivers" ${ }^{[11]}$. It is predicted that within the next 50 years, the total number of cancer cases is expected to double, thereby likely increasing the prevalence of informal caregiving. Informal caregiving is often a mentally, socially, and emotionally overwhelming experience that can engender a profound sense of loneliness. Referring to caregivers, we address not the professional, employed ones, but those family members or friends who are by the patient's side. Even if caregivers are able to find time to engage in social activities, they may be less able to derive concomitant psychological benefits if they feel guilty and anxious seeing that they are "giving up temporarily" their caregiving responsibilities ${ }^{[42]}$. Caregiving, in general, being so very demanding can disrupt one's working schedule, family life, and social relationships, thus rendering it difficult to maintain desired levels of social involvement ${ }^{[42]}$. Being the sole primary caregiver (as is often the case), may result in caregivers feeling unsupported by family and friends who go on with their lives, thus compounding their sense of loneliness ${ }^{[42]}$. Finally, seeing the suffering of a loved one without being able to ease the pain or prevent death, as well as, facing one's own mortality, may result in loneliness and alienation from the rest of the healthy and bustling society ${ }^{[7]}$. It is, therefore, obvious why caregiving is frequently associated with significant psychological and physical vulnerability, which may include depression, anxiety, anger, health problems, loneliness and suicidality ${ }^{[23]}$.

Commenting on the effect of death or expected death of a loved one, Rainer and McMurry ${ }^{[23]}$ noted that "the physical changes that accompany the dying of a loved one can be difficult to watch and often impossible to understand. Adding to it the mental, spiritual, social and emotional adjustments may make this event overwhelming" (p. 1421). Caring for a dying person creates considerable strain for caregivers and may affect their working schedule, family life, and social relationships. It is, consequently, of no surprise that caregiving is frequently associated with significant physical and psychological vulnerability. Their distress is evident in the form of depression, anxiety, anger, health problems, and loneliness. Alarmingly, $14 \%$ of caregivers admitted entertaining suicidal thoughts ${ }^{[7]}$.

\subsection{Loneliness of caregivers}

Caregivers are sometimes called "The hidden patients" because they are caring for a family member whose care needs are very significant, and in addition also manage their own life and personal needs. Some of the more obvious risks of the caregiving include depression, fatigue, physical illness and emotional exhaustion ${ }^{[11]}$.

The debilitating effects of loneliness in various spheres of life are well-supported ${ }^{[20]}$. Research has found loneliness to be inversely related to life satisfaction, healthy personality integration, and mental health, and may result in depression ${ }^{[5,15]}$ and anxiety ${ }^{[30]}$. Loneliness may represent one intrapersonal construct that can serve as a contributing link between cancer and the above mentioned distress. As such, it is important to examine the loneliness experience so that we may better understand a potential source of distress among individuals whose lives have been affected by their own or their loved one's cancer (see also ${ }^{[38]}$ ).

Thus, not only do individuals who care for cancer patients have to cope with the disease that their loved ones have, but the resultant loneliness may serve to exacerbate the psychological, social, and physical distress that accompany the diagnosis of cancer.

\subsection{Palliative care}

Dying, according to the movement that gave rise to palliative care, is a normal process, rather than as a medical failure as it is considered by main stream medicine. Palliative care holds that it should not hasten nor postpone death, while helping patients to be as pain free, and comfortable on their journey towards death. Cushing, the noted physician, remarked that "A physician is obligated to consider more than the diseased organ, more even than the whole man - he must view the man in his world" (in ${ }^{[13]}$ ). Palliative care offers a support system to the patient and to his (often) distressed family. Twycross ${ }^{[39]}$ 
maintained that when health restoration is no longer possible, care and not cure should be the focus. Palliative care, thus, offers a support system that enables and encourages patients to live as actively as possible until death, and helps the family cope [during the patient's illness] with their pain over the illness and their anticipatory grief ${ }^{[13,37]}$.

The present research project was sparked by the first author's observation, while accompanying his dying father in the hospital and later in the hospice, of the immense isolation and distress of hospice caregivers, and consequently the pressure and expectations of the attending nursing staff, thus prompting the idea of comparing the coping strategies of caregivers of those afflicted with cancer, but are in different trajectories: caregivers of those who receive treatment and look forward to a possible recovery, and those who are approaching the end of their stay on earth.

\section{Method}

\subsection{Participants}

Five hundred and forty one participants volunteered to partake in the study. A total of 201 men and 340 women comprised the sample, which took about a year to assemble. The average age of all participants was 44 years, with ages ranging between 16-88. The mean level of education (i.e. last grade completed) was 14 years with a range of 4-24. Twenty-one percent of participants were single, $70 \%$ were married, and $9 \%$ had a past relationship but were no longer in it due to separation, divorce or death of a spouse (see Table 1).

Table 1. Demographics

\begin{tabular}{|c|c|c|c|c|c|c|c|c|c|c|c|c|}
\hline \multirow{2}{*}{ Population } & \multirow{2}{*}{$\mathbf{N}^{\varepsilon}$} & \multicolumn{2}{|c|}{ Gender } & \multirow{2}{*}{$\begin{array}{l}\text { Married/ } \\
\text { living } \\
\text { with } \\
\text { partner }\end{array}$} & \multicolumn{4}{|c|}{ Marital status } & \multicolumn{2}{|c|}{ Education } & \multicolumn{2}{|c|}{ Age } \\
\hline & & Male & Female & & separated & divorced & widower & single & M & SD & M & SD \\
\hline \multirow[t]{2}{*}{ Hospice } & 101 & 42 & 59 & 81 & 0 & 8 & 3 & 10 & 14.50 & 3.34 & 41.50 & 15.27 \\
\hline & & $42 \%$ & $58 \%$ & $79 \%$ & $0 \%$ & $8 \%$ & $3 \%$ & $10 \%$ & $(4-24)^{\epsilon}$ & & $(21-88)$ & \\
\hline \multirow[t]{2}{*}{ Oncology } & 440 & 159 & 281 & 296 & 13 & 15 & 9 & 104 & 14.04 & 2.61 & 55.17 & 15.59 \\
\hline & & $36 \%$ & $64 \%$ & $68 \%$ & $3 \%$ & $3 \%$ & $2 \%$ & $24 \%$ & $(8-24)$ & & $(16-84)$ & \\
\hline \multirow[t]{3}{*}{ Total } & 541 & 201 & 340 & 377 & 13 & 23 & 12 & 114 & 14.13 & 2.76 & 44.05 & 16.21 \\
\hline & & $37 \%$ & $63 \%$ & $70 \%$ & $3 \%$ & $4 \%$ & $2 \%$ & $21 \%$ & $(4-24)$ & & $(16-88)$ & \\
\hline & & \multicolumn{2}{|c|}{$\chi_{(1)}^{2}=1.04$} & & & \multicolumn{2}{|c|}{$\chi_{(4)}^{2}=16.36^{*}$} & & \multicolumn{2}{|l|}{$\mathrm{t}_{(527)}=1.44$} & \multicolumn{2}{|l|}{$\mathrm{t}_{(529)}=8.00^{\#}$} \\
\hline
\end{tabular}

${ }^{*} p<.01 \quad{ }^{\#} p<.001{ }^{£}$ Frequencies might not add up due to missing data. ${ }^{\epsilon}$ Range in parentheses.

No significant differences were found in gender and in education between the two groups. There were significant differences in marital status and in age between the two groups. Age was covaried in analyses.

\subsection{Procedure}

Caregivers were recruited in an oncological department in a major hospital in central Israel, and in a hospice catering to cancer patients, also in central Israel. They were eligible if they had been identified as accompanying a patient suffering from and being treated for cancer. The Institutional Review Boards of both institutions (Ichilov \& Tel HaShomer hospitals) reviewed and approved the study.

Each caregiver was approached in the patient's hospital room by the departmental head nurse (in the hospital) or the hospice director (in the hospice) and was invited to participate in a study investigating the experience of loneliness. 
Participants were then asked to complete a battery of measures including a demographic questionnaire, and a questionnaire of coping with loneliness.

In an attempt to overcome the methodological limitations of other studies relying solely on college students (see ${ }^{[22,25]}$, caregivers, naturally, represent the general population. No financial compensation was provided for participants. They were told that they could request a summary of the research results if desired, and accordingly, provide their contact information on a separate piece of paper so as to maintain their anonymity. The consent was a verbal one, where the patients were explained what the study is about, and invited to participate, assuring them of anonymity and that they could drop out at any time, with no adverse consequences. Should patients or caregivers feel stressed as a result of the study, we made arrangements to provide psychological support, but none was needed or requested. Data collection lasted from January 2011 to June 2012.

\subsection{Coping with loneliness questionnaire}

The Coping with Loneliness Questionnaire ${ }^{[25]}$ is a yes/no measure consisting of 34 statements that describe the beneficial strategies of coping with loneliness. The strategies were grouped into six subscales:

a. Acceptance and reflection = being by one's self to become acquainted with one's fears, wishes and needs; and consequently, accepting one's loneliness and resultant pain ("I turned loneliness into a time for reflection" "I came to accept how I felt');

b. Self development and understanding $=$ the increased self-intimacy, renewal, and growth which are often the results of active participation in organized focused groups or of receiving professional help and support ("I sought professional help from a medical doctor" "I enrolled in personal development seminars");

c. Social support network $=$ the re establishing of social support network which can help one feel connected to and valued by others ("I renewed old friendships" "I spent time at places where I knew there would be a lot of people");

d. Distancing and denial = denial of the experience and pain of loneliness by alcoholism, drug abuse, and other deviant behaviours ("I purposely built walls around myself" "I denied to myself that anything was wrong");

e. Religion and faith $=$ the need to connect to and worship a divine entity. Through affiliation with a religious group and practicing its faith one can gain strength, inner peace, and a sense of community and belonging ("I sought answers to my problems in prayer" "My attendance at religious services increased"); and

f. Increased activity = active pursuit of daily responsibilities as well as fun-filled solitary or group activities as well, thus maximizing one's social contacts ("I got a part-time job" "I took up a new hobby").

\subsection{Scoring and reliability}

The score for each factor could range between zero and a maximum of six. Kuder-Richardson reliabilities, calculated on the present sample are: Reflection $\&$ acceptance $=.72$; Self-development $\&$ understanding=.34; Social support network $=.65$; Distancing $\&$ denial $=.23$; Religion $\&$ faith $=.62$; Increased activity $=.49 . \mathrm{K}-\mathrm{R}$ alpha for all the 34 items $=.78$.

\section{Results}

In general, we found no significant difference in the quality of loneliness experienced in the caregivers of the two groups: those oncology patients who were battling cancer, and those on their deathbed. We found significant differences only in the caregiver group who were attending the oncology patients, where women had higher scores on Reflection \& acceptance, Self-development and understanding, and social support network. 
Table 2. Comparing mean scores of coping with loneliness strategies by institute and gender

\begin{tabular}{|c|c|c|c|c|c|c|c|c|c|c|c|c|c|}
\hline \multirow[t]{2}{*}{ Population } & \multirow[t]{2}{*}{$\mathbf{N}^{\mathbf{a}}$} & \multicolumn{2}{|c|}{$\begin{array}{l}\text { Reflection \& } \\
\text { acceptance }\end{array}$} & \multicolumn{2}{|c|}{$\begin{array}{l}\text { Self-development } \\
\text { \& understanding }\end{array}$} & \multicolumn{2}{|c|}{$\begin{array}{l}\text { Social } \\
\text { support } \\
\text { network }\end{array}$} & \multicolumn{2}{|c|}{$\begin{array}{l}\text { Distancing } \\
\text { \& denial }\end{array}$} & \multicolumn{2}{|c|}{$\begin{array}{l}\text { Religion \& } \\
\text { faith }\end{array}$} & \multicolumn{2}{|c|}{$\begin{array}{l}\text { Increased } \\
\text { activity }\end{array}$} \\
\hline & & M & SD & M & SD & M & $\mathrm{SD}$ & M & SD & M & SD & M & $\mathrm{SD}$ \\
\hline Dying (total) & 99 & 1.71 & 1.81 & 0.41 & 0.78 & 0.85 & 1.13 & 0.16 & 0.42 & 0.17 & 0.47 & 0.79 & 1.09 \\
\hline Male & 40 & 1.83 & 1.88 & 0.27 & 0.60 & 0.83 & 1.06 & 0.10 & 0.35 & 0.22 & 0.58 & 0.73 & 1.13 \\
\hline female & 59 & 1.63 & 1.77 & 0.51 & 0.88 & 0.86 & 1.18 & 0.22 & 0.46 & 0.14 & 0.39 & 0.83 & 1.07 \\
\hline \multicolumn{14}{|l|}{$\begin{array}{l}\text { MANCOVA }^{2} \\
F_{(6,91)}=1.15\end{array}$} \\
\hline Oncology (total) & 432 & 2.23 & 1.86 & 0.45 & 0.74 & 1.35 & 1.49 & 0.21 & 0.48 & 0.36 & 0.76 & 1.23 & 1.22 \\
\hline Male & 155 & 1.81 & 1.79 & 0.26 & 0.51 & 1.11 & 1.35 & 0.24 & 0.54 & 0.28 & 0.74 & 1.14 & 1.20 \\
\hline Female & 277 & 2.47 & 1.86 & 0.56 & 0.83 & 1.49 & 1.55 & 0.20 & 0.44 & 0.41 & 0.76 & 1.28 & 1.22 \\
\hline $\begin{array}{l}\text { MANCOVA }^{\epsilon} \\
F_{(6,424)}=5.01^{\varepsilon}\end{array}$ & & \multicolumn{2}{|c|}{$\begin{array}{l}\mathrm{F}_{(1,429)}=11.72^{\#} \\
\eta^{2}=0.03\end{array}$} & \multicolumn{2}{|c|}{$\begin{array}{l}\mathrm{F}_{(1,429)}=18.44^{\#} \\
\eta^{2}=0.04\end{array}$} & \multicolumn{2}{|c|}{$\begin{array}{l}\mathrm{F}_{(1,429)}=5.32^{*} \\
\eta^{2}=0.01\end{array}$} & \multicolumn{2}{|c|}{$\mathrm{F}_{(1,429)}=1.01$} & \multicolumn{2}{|c|}{$F_{(1,429)}=2.70$} & \multicolumn{2}{|c|}{$\mathrm{F}_{(1,429)}=1.06$} \\
\hline Total & 531 & 2.14 & 1.86 & 0.45 & 0.75 & 1.26 & 1.45 & 0.20 & 0.47 & 0.36 & 0.76 & 1.15 & 1.20 \\
\hline \\
\hline \multicolumn{14}{|l|}{ MANCOVA $^{\epsilon}$} \\
\hline \multicolumn{14}{|l|}{$F_{(6,523)}=1.08$} \\
\hline \multicolumn{14}{|l|}{ Male Dying. Vs. } \\
\hline \multicolumn{14}{|l|}{ Oncology. } \\
\hline \multicolumn{14}{|l|}{$F_{(6,187)}=0.67$} \\
\hline \multicolumn{14}{|l|}{ Female Dying vs. } \\
\hline \multicolumn{14}{|l|}{ Oncology } \\
\hline$F_{(6,328)}=1.94$ & & & & & & & & & & & & & \\
\hline
\end{tabular}

Table 2 compared the mean subscale scores on each of the six subscales of coping with loneliness among the two groups, among the genders in each group and within the gender across groups, using a MANCOVA (age was covaried). Generally, no significant differences were found among the two groups $(\mathrm{F}(6,523)=1.08$; n.s.). No significant gender differences were found in caregivers of the dying $(\mathrm{F}(6,91)=1.15$; n.s.). Significant gender differences were found in the caregiver group who were attending to the oncology patients $(\mathrm{F}(6,424)=5.01, p<.001)$.Univariate ANCOVAs for each of the subscales across genders revealed that women had higher subscale scores on three subscales: Reflection \& acceptance $(\mathrm{F}(1,429)=11.72$, $p<.01)$, Self-development \& understanding $(\mathrm{F}(1,429)=18.44, p<.01)$ and Social support network $(\mathrm{F}(1,429)=5.32, p<.05)$. No significant differences were found between men caregivers in the oncology department and men attending to the dying $(F(6,187)=0.67 ;$ n.s. $)$ or between women caregivers in oncology and women attending to the dying $(F(6,328)=1.94)$.

\section{Discussion}

Life is a journey and death is its final destination, and death as we know, may be the only common bond that we all share. Death, and the illness that may lead to it, are not only distressing and overwhelming, but are accompanied by loneliness both, for the patient and for those who care for them ${ }^{[7]}$. The present study examined that very loneliness, the loneliness of the caregivers to the ill and to the dying. What we focused on, was not the quantity or intensity of loneliness, but rather how those people cope with the loneliness which may be such an integral part of caregivers. The present results indicate that overall, there were no significant differences in the strategies utilized to cope with loneliness between the two caregiver groups. As we pointed out earlier, caregivers to the ill and dying similarly experience stress, and societal 
alienation and consequent difficulties that they may encounter as a result of taking care of the dying (see ${ }^{[2,34,44]}$. It, thus, stands to reason that their coping strategies will be similar, as we found in the present study.

\subsection{Caregivers' burden and loneliness}

While caring for a loved one, grieving for those who are on 'their way out', and experiencing a host of emotions as well as loneliness ${ }^{[19,32]}$, caregivers as a group are commonly isolated from social support ${ }^{[32]}$. Inversely, support may sometimes be too intrusive and be offered in quantities and intensities with which the stressed caregivers may not be able to handle, or may not utilize when addressing and coping with their own loneliness. Consequently, caregivers, regardless of whether they are caring for the ill or the dying, may cope with loneliness in a similar, if not identical, manner (see also ${ }^{[31]}$, and gender would, as well, not make a difference as to how they cope with loneliness ${ }^{[6]}$.

In our study we compared the subscale scores of males and females caring for the dying, males across the two groups, and females across the two groups. There were no significant differences found between the caregiver groups, possibly meaning that these people react to and cope with loneliness and to their burden of caregiving in a similar manner (see ${ }^{[6,21]}$ ). The only group where we did find significant differences between the genders, was in those caring for the ill, on Reflection \& acceptance [which addressed the ability to be by one's self and so, become aware of one's fears, wishes and needs, and as a result, accept one's loneliness and its related pain], Self-development and understanding [addressing the increased self-intimacy, renewal, and growth which are often a consequence of attending organized support groups or of receiving professional help and support], and the Social support network subscales[which addresses the establishing of social support network which helps in receiving support, encouragement and can help one feel connected to and valued by others]. Women caregivers scored significantly higher on those three subscales than men did. That is an interesting result, since there were no other significant differences between the genders, but in this group.

\subsection{Gender differences in loneliness}

Rokach and Brock ${ }^{[26]}$ found consistent differences in the reported experiences of loneliness between North American men and women. The present result is in line with previous research that highlighted women's socialization in the Western world. Women are more adept than men at self-reflection, expressing their emotions, and being tuned into what they feel and how they act (see for example ${ }^{[28]}$ ). Riches ${ }^{[24]}$ highlighted the loneliness that is commonly experienced by the ill and the dying and by their caregivers. During this period of illness, treatments and questions about the patient's future, we would intuitively expect that caregivers will engage in reflection about their situation and it's ramification on their own future. It may help explain the higher scores that women received on the Acceptance \& reflection subscale, since men are culturally not trained, or encouraged, to reflect and attend to their emotions ${ }^{[30]}$. The demanding nature of caregiving can disrupt one's working schedule, family life, and social relationships, thus rendering it difficult to maintain desired levels of social involvement ${ }^{[42]}$. Even if caregiver women are able to find time to engage in social activities, they may be less able to derive concomitant psychological benefits if confronted with guilt and anxiety around their reprieve from caregiving ${ }^{[42]}$.

Women in the ill group also scored higher on Self-development \& understanding. It may be that they continued to attend book clubs, meet with other women, and consult with their physician or therapist which women in the Western culture are more apt to do than men. Similarly, these caregiver women have scored higher than men on Social support network. Social support can buffer the negative impact of stressful life events on psychological distress, depression, and anxiety as well as alleviate one's loneliness (e.g. ${ }^{[10,14]}$ ). Perceived social support is a "relationship transaction" characterized by the subjective receipt of psychological resources intended to bolster one's ability to cope with stress ${ }^{[9,43]}$. The current literature suggests that the critical factor that may buffer stress is the perception that one is socially supported and can rely on someone for help when the need arises ${ }^{[40]}$. Social support may aid the person to change his appraisal of a stressful situation, subsequently reducing the level of perceived stress and dampening the emotional and physiological response to the event ${ }^{[41]}$. As the literature indicated, women's socialization makes it more natural for them to socialize, connect with others, share experiences, and weave a support network in ways that men usually do not do ${ }^{[30]}$. 


\subsection{Where we did not find gender differences}

It appears that both genders employ the other three coping techniques in a similar manner, meaning that there is no significant difference in the manner that men and women in both groups engage in Distancing and denial, Religion and Faith, and Increased activity. Caregivers of ill patients mostly focus on their caregiving responsibilities. Needless to say, only the healthy and those not involved in caregiving may get involved in work and extracurricular activities; domains which are no longer available (or relevant) to caregivers of patients during treatment and hospitalization, or to the dying. And as Syren et al ${ }^{[36]}$ observed that "when the awareness of mortality became obvious, the future [is] experienced as dramatically limited and plans [are] made for just the immediate future" (p. 30). It is suggested that both during treatment and when the patient is on his death bed, caregivers and patients alike, may engage in some denial of the grave situation, as well as prayers and religious practices in the hope of helping the patient and themselves. It is, therefore, not surprising that no significant differences in subscale scores were observed between the genders in this group. It is also suggested that since there was no measure, in this study of the level of loneliness in the sample, it is not known whether the level of loneliness of participants could explain the lack of significant results.

\subsection{In conclusion}

To conclude, it was found that there was no significant difference in coping with loneliness reported by caregivers to cancer stricken hospitalized patients, and those who cared who for patients dying of cancer in a hospice. The only significant difference was found between men and women caring for the ill. Women scored significantly higher than men on the Reflection and acceptance, Self-development and understanding, and the social support network subscales. There is no question, and there is ample research to support it [see, for instance, ${ }^{[8,30]}$ ) that cancer patients as well as their caregivers struggle not only with the threat of a terminal illness, but with a painful loneliness that may exacerbate their symptoms and add to their demands of the nursing staff. Thus, it would be helpful, for patients and nurses alike, if the staff attended to the patients' emotional and spiritual needs, in addition to the medical care that they provide, and if volunteers from the community [or even nursing students] would drop in, visit with the patients and their caregivers, and and help them cope with their anxiety, loneliness, and isolation.

The present study's limitations, which future research could address, are related to the lack of ascertaining the relationship between the patient and the caregiver [i.e. parent, child, spouse, etc.], and whether the caregiver is sole carer or is one amongst several who care for the patient. Future research could explore the influence of the kind of disease [where the cancer is located], and where is the person spending his or her last days in a hospice, hospital, or at home on the strategies utilized to cope with loneliness. Future research could also measure the level of loneliness in both groups and explore the interaction of the intensity of loneliness with the coping strategies utilized.

\section{References}

[1] National Family Caregiver Alliance. National policy statement. 2009. Available from http://www.caregiver.org/caregiver/jsp/content_node.jsp?nodeid $1 / 42279$

[2] Belsky JK. The Psychology of aging: Theory, research and interventions (3rd Ed.) Toronto, ON: Brooks/Cole; 1999.

[3] Bloom JR, Spiegel D. The relationship of two dimensions of social support to the psychological well being and social functioning of women with advanced breast cancer. Social Science and Medicine. 1984; 19: 831-837. http://dx.doi.org/10.1016/0277-9536(84)90400-3

[4] Cacioppo JT, Fowler JH, Christakis NA. Alone in the crowd: The structure and spread of loneliness in large social network. Journal of Personality and Social Psychology. 2009; 97(6): 977-991. http://dx.doi.org/10.1037/a0016076

[5] Cacioppo JT, Hawkley LC. Loneliness. In M.R. Leary \& R.H. Hoyle (Eds.). Handbook of individual differences in social behavior (pp.227-239). New York: Guilford; 2009.

[6] Chappell NL, Dujela C. Caregiving: Predicting At-Risk Status. Cana $\neg$ dian Journal on Aging. 2008; 27: 169-79. http://dx.doi.org/10.3138/cja.27.2.169 
[7] Chentsova-Dutton, Y, Shucter S, Hutchin S, et al. Depression and grief reactions in hospice caregivers: From pre-death to 1 year afterwards. Journal of Affective Disorders. 2002; 69: 53-60. http://dx.doi.org/10.1016/S0165-0327(00)00368-2

[8] Chin J, Findler L, Rokach A, Lev S, Kollender Y. The experience of loneliness among cancer patients and their caregivers. International Journal of Psychological Research. 2013; 8(2): 1-17.

[9] Cohen S. Social relationships and health.American Psychologist. Special Issue: Awards Issue. 2004; 59: 676-684.

[10] Demir M, Ozdemir M, Weitekamp LA. Looking to happy tomorrows with fiends: Best and close friendships as they predict happiness. Journal of Happiness Studies. 2007; 8: 6-12. http://dx.doi.org/10.1007/s10902-006-9025-2

[11] Dwyer TF. Family caregiving across the lifespan. Family Therapy. 2011; 10(1): 18-21. 243-271.

[12] Friedman G, Florian V, Zernitsky-Shurka E.The experience of loneliness among young adult cancer patients.Journal of Psychosocial Oncology. 1989; 7: 1-15. http://dx.doi.org/10.1300/J077v07n03_01

[13] Faull C, Woof R. Palliative care: An Oxford core text. New York: Oxford University Press; 2002.

[14] Hawkley LC, Thisted RA, Masi CM, Cacioppo JT. Loneliness predicts increased blood pressure: 5-Year cross-lagged analyses in middle-aged and older adults. Psychology and Aging. 2010; 25(1): 132-141. http://dx.doi.org/10.1037/a0017805

[15] Heinrich LM, Gullone E. The clinical significance of loneliness: A literature review. Clinical Psychology review. 2006; 26: 695-718. http://dx.doi.org/10.1016/j.cpr.2006.04.002

[16] Hinds PS. "How bad is it?'”: The role of nursing research in prognostication. Cancer Nursing. 2010; 33: 83-84. http://dx.doi.org/10.1097/NCC.0b013e3181d1c8d1

[17] Hoke LA. Psychosocial adjustment in children of mothers with breast cancer.Psychooncology. 2001; 10: 361-369. http://dx.doi.org/10.1002/pon.515

[18] Jones WH, Rose J, Russell D. Loneliness and social anxiety. In H. Leitenberg (Ed), Handbook of social and evaluation anxiety (p. 247-266). Plenum: New York; 1990. http://dx.doi.org/10.1007/978-1-4899-2504-6_9

[19] Kresting K. Improving the end of life for older adults. Monitor on Psychology. 2004; 35(10): 53-54.

[20] Lofvenmark C, Mattiasson AC, Billing E, Edner M. Perceived loneliness and social support in patients with chronic heart failure. European Journal of Cardiovascular Nursing. 2009; 8: 251-258. http://dx.doi.org/10.1016/j.ejcnurse.2009.05.001

[21] Mendez-Luck C, Kennedy D, Wallace S. Concepts of Burden in Giving Care to Older Relatives: A Study of Female Caregivers in a Mexico City Neighbourhood. Journal of Cross-Cultural Gerontology. 2008; 23: 265-82.

http://dx.doi.org/10.1007/s10823-008-9058-6

[22] McWhirter BT. Review of current literature with implications for Counselling and Research.Journal of Counselling and Development. 1990; 68(4): 417-422. http://dx.doi.org/10.1002/j.1556-6676.1990.tb02521.x

[23] Rainer JP, McMurry PE. Caregiving at theend of life.Psychotherapy in Practice. 2002; 58: 1421-1431.

[24] Riches G. The loss of children: thinking the unthinkable. In C. Mason (Ed.).Journeys into palliative care: Roots and reflection (pp. 135-153). London, UK: Jessica Kingsley Pub; 2002.

[25] Rokach A. Coping with loneliness among the terminally ill. Social Indicators Research. 2007; 82: 487-503. http://dx.doi.org/10.1007/s11205-006-9047-5

[26] Rokach A, Brock H. Coping with loneliness. Journal of Psychology. 1998; 132(1): 107-127. http://dx.doi.org/10.1080/00223989809599269

[27] Rokach A, Findler L, Chin J, Lev S, Kollender Y. Cancer patients, their caregivers, and coping with loneliness. Psychology, Health \& Medicine. 2013; 18(2): 135-144. http://dx.doi.org/10.1080/13548506.2012.689839

[28] Rokach A, Orzeck T, Moya M, Exposito F. Loneliness in North America and Spain. Social Behaviour and Personality: An International Journal. 2001; 29(5): 477-490. http://dx.doi.org/10.2224/sbp.2001.29.5.477

[29] Rokach B, Rokach A. Medicine, radiology, hospitalization, and loneliness. In A. Rokach, [Editor] Loneliness updated: Recent research on loneliness and how it affects our life (pp. 270-283). Abingdon, UK: Routledge; 2013.

[30] Rokach A, Sha'ked A. Together and lonely: Loneliness in Intimate relationships - Causes and coping. NY: Nova Pub; 2013.

[31] Schoenmakers B, Buntinx F, Delepeleire J. Factors determining the impact of care-giving of elderly patients with dementia: A sytematic literature review. Maturitas. 2010; 66: 191-200. http://dx.doi.org/10.1016/j.maturitas.2010.02.009

[32] Schwartz L, Drotar D. Effects of written emotional disclosure on caregivers of children and adolescents with chronic illness.Journal of Pediatric Psychology. 2004; 29(2): 105-118. http://dx.doi.org/10.1093/jpepsy/jsh014

[33] Singer BA. Psychosocial trauma, defense strategies, and treatment considerations in cancer patients and their families. American Journal of the Family. 1983; 11: 15-21. http://dx.doi.org/10.1080/01926188308250131

[34] Stambor Z. Caring for caregivers. Monitor on Psychology. 2006; 37(10): 46-47.

[35] Stearns N, Lauria M, Hermann F, Fogelberg P. Oncology social work: A clinician's guide. New York: American Cancer Society; 1993.

[36] Syren SM, Britt-Inger S, Benzein EG. Being a family in the midst of living an dying. Journal of palliative care. 2006; $22(1)$ : 26-32. 
[37] Tang SL, McCorkle R, Bradley EH. Determinants of death in an inpatient hospice for terminally ill cancer patients.Palliative and SupportiveCare. 2004; 2: 361-370. http://dx.doi.org/10.1017/S1478951504040489

[38] Tomaka J, Thompson S, Palacios R. The relation of social isolation, loneliness, and social support to disease outcomes among the elderly.Journal of Aging and Health. 2006; 18: 359-384. http://dx.doi.org/10.1177/0898264305280993

[39] Twycross R. Introducing palliative care (4th edition). Oxon, UK: Radcliffe Medical Press; 2003.

[40] Uchino BN, Cacioppo JT, Kiecolt-Glaser JK. The relationship between social support and physiological processes: A review with emphasis on underlying mechanisms and implications for health. Psychological Bulletin. 1996; 119: 488-531. http://dx.doi.org/10.1037/0033-2909.119.3.488

[41] Wills TA, Cleary SD. How are social support effectsmediated? A test with parental support and adolescent substanceuse.Journal of Personality and Social Psychology. 1996; 71(5): 937-952. http://dx.doi.org/10.1037/0022-3514.71.5.937

[42] Wittenberg-Lyles E, Demiris G, Oliver, DP, Burt S. Reciprocal suffering: Caregiver concerns during hospice care. Journal of Pain and Symptom Management. 2011; 41: 383-393. http://dx.doi.org/10.1016/j.jpainsymman.2010.04.026

[43] Zimet GD, Dahlem NW, Zimet SG, Farley GK. The multidimensional scale of perceived social support.Journal of Personality Assessment. 1988: 52(1): 30-41. http://dx.doi.org/10.1207/s15327752jpa5201_2

[44] Zuckerman C. Till death do us part: family caregiving at the end of life. In: C. Levene [Ed]. Always on Call: WhenIllness Turns Families Into Caregivers (pp.176-192). Nashville, Tenn: Vanderbilt University Press; 2004. 